\title{
Correlation between dust events in Mongolia and surface wind and precipitation
}

\author{
Ganbat Amgalan ${ }^{1}$, Gin-Rong Liu ${ }^{1,2, *}$, Tang-Huang Lin ${ }^{2}$, and Tsung-Hua Kuo ${ }^{2}$ \\ ${ }^{1}$ Department of Atmospheric Sciences, National Central University, Taoyuan City, Taiwan \\ ${ }^{2}$ Center for Space and Remote Sensing Research, National Central University, Taoyuan City, Taiwan
}

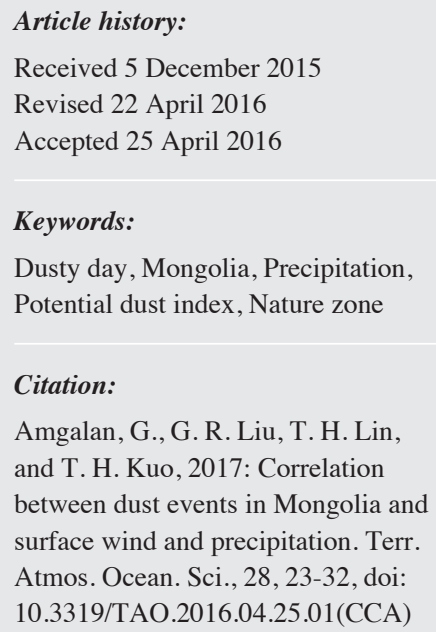

\begin{abstract}
This study presents dust event spatiotemporal distribution and regional trends, and the impact of surface wind and precipitation on dust occurrences in Mongolia. We used data collected between 2000 and 2013 from 113 meteorological stations in natural forest steppe, steppe, Gobi Desert, and mountain zones. We analyzed the relationship between dusty days, derived using the sum of days with dust storms and/ or drifting dust, and days with strong winds (at a threshold wind speed of a constant $6.5 \mathrm{~m} \mathrm{~s}^{-1}$, hereafter, strong wind days) and precipitation by comparing the dusty days in dust-frequent years, dust-less years, and dust-mean years. Dusty days in dust-frequent years were associated with strong wind days when the precipitation is about $10 \mathrm{~mm}$ and dust occurrences were suppressed by large amounts of precipitation (approximately $22 \mathrm{~mm}$ ) in dust-less years over the southeastern part of the Gobi Desert in May. We propose a potential dust index (PDI) based on the correlations among dusty days, strong winds and precipitation. The PDI performed as predicted in most areas of the country in the spring season.
\end{abstract}

\section{INTRODUCTION}

Dust is a type of aerosol with one of the highest atmospheric mass loads on a global scale. Dust storms are natural phenomena. They can result in severe ecological and environmental problems. Many scientists have studied how dust storms impact human life, society and the economy, and climate change (Kwon et al. 2002; Chen et al. 2004; Park et al. 2005). Some studies estimated that up to $50 \%$ of the current atmospheric dust load originates from anthropogenically disturbed surfaces (Tegen and Fung 1995). The radiative forcing from aerosols cannot be accurately computed, but dust is believed to be an important component of the Earth's climate system (IPCC 2007).

Asian dust is the second largest aeolian dust source on Earth, and it impacts the global climate (Miller et al. 2004). Asian dust has advanced rapidly in the past decade (Iwasaka 2006; Goudie and Middleton 2006; Shao and Dong 2006). Dust storms with strong northeasterly winds generated in arid areas of Central Asia can transport material to Taiwan (Liu and Lin 2004; Lin et al. 2004). Furthermore,

\footnotetext{
* Corresponding author

E-mail:grliu@csrsr.ncu.edu.tw
}

material can be transported as far away as the west coast of the United States and southern British Columbia, Canada (McKendry et al. 2001).

Dust emission models have provided valuable information, but they are associated with uncertainties such as a lack of related soil data and the soil surface characteristics, and relationship between dust emissions and soil and surface characteristics (Uno et al. 2006). Recent research has suggested that additional detailed studies are necessary to better understand the temporal changes in dust sources, transportation features and related governing factors (Hara et al. 2006; Tian et al. 2007; Natsagdorj 2009).

A previous climatological studies on dust storms (Natsagdorj et al. 2003) used data from 1937 - 1999 from 49 meteorological stations and historical observations to show that Mongolian dust exhibits large annual variability. Mongolia's ecosystems have clearly changed as a result of climate change and human activities. Examples of these changes include desertification, soil erosion, and natural disasters such as dust storms, drought, extreme weather events, etc. (Batima and Dagvadorj 2000). A recent assessment in Mongolia indicated that the desert zone is tending to expand to 
the north (MARCC 2010). This finding highlights why a detailed study of dust significance is necessary in the growing field of Earth system science.

This study used comprehensive data from 2000 - 2013 attempts to characterize the spatiotemporal distribution of dust events and focusing on how dust events correlate with surface wind and precipitation. The objective of this study is to spatially examine dust occurrences focusing on the basic four natural zones in Mongolia. Results from some studies have implied that precipitation may be one of the primary factors controlling dust occurrences (Sun et al. 2001; Zou and Zhai 2004). It is important to improve our understanding of the physical relationships between surface conditions and dust events. Eventually, an index is expected to be constructed for forecasting potential dust events in Mongolia.

\section{DATA USED AND METHODS}

We used synoptic surface wind velocity observation data at a height of $10 \mathrm{~m}$ collected every three hours and daily precipitation measurements. These data were obtained from 113 meteorological stations throughout the 2000 2013. These stations are distributed evenly over the territory of Mongolia. These data were provided by the Institute of Meteorology and Hydrology of Mongolia (IMH). The meteorological station locations and the seven natural zones are shown in Fig. 1. For discussion convenience all stations were categorized into four zones: forest steppe, steppe, Gobi Desert (Gobi and Desert zones), and the Altai Mountains (hereafter, mountains).

According to the data from the U.S. Geological Survey (Loveland et al. 2000), the major land cover types are semi-desert shrubs and high-erodibility in the Gobi Desert, grassland in northern Mongolia, and semi-desert shrubs and grassland in western Mongolia.

We obtained dust storm data using naked-eye observations in accordance with the Meteorological Observations Manual of Mongolia (IMH 2009). As a result of strong turbulent wind systems entraining dust particles in the air, visibility is reduced less than $10 \mathrm{~km}$. If dust is raised by the wind and the visibility is not reduced below $10 \mathrm{~km}$ at eye level, the phenomenon is called drifting dust. Dusty days are defined the sum of days with dust storms and/or drifting dust. We counted the number of days corresponding to dust storms or drifting dust according to daily intervals of 24 hours from 20:00 (Ulaanbaatar local time, ULT, UTC+8). If a dust event (dust storm or drifting) persists past 20:00 ULT, the event is counted as occurring over two days. On the other hand, if there are several dust events in a day, the sum phenomenon is recorded as only occurring over one day (Puntsagdorj 2014). Dust storm days and dusty days are defined as those occurring in one month or one year. A strong surface wind is defined as a velocity exceeding $6.5 \mathrm{~m} \mathrm{~s}^{-1}$ (a constant threshold), which is the threshold for dust emissions for many dust storm numerical models (Tegen and Fung 1995; Kurosaki and Mikami 2003; Natsagdorj et al. 2003). Similarly, strong wind days are defined as the number of dust event days. We used statistical analyses to explore our objectives.

\section{RESULTS AND DISCUSSIONS}

\subsection{Dust Storm and Dusty Days}

The distributions of annual dust storm days and dusty days are shown in Fig. 2. Dust storm days number $<5$ over the northern part of Mongolia and more than 30 days, the conventional source of dust storms, covered the southeastern and western parts of Mongolia. The dense vegetation canopy, more pronounced surface roughness and corresponding wetness are the causes behind the lower dust occurrence in the forest steppe zone. The Gobi Desert is drier with a low relative humidity $(\sim 54 \%)$ and less precipitation (approximately $50-120 \mathrm{~mm}$ over 2000 - 2013). It is the warmest climate region in Mongolia. These conditions are consistent with the results of Goudie (1983). These authors found that dust events were most common in areas where the rainfall was between 100 and $200 \mathrm{~mm}$ per year.

The numbers of dusty day between 90 and 107 days over the south side of the Altai Mountains and 60 - 90 days over the Gobi Desert zone. These distributions are consistent with the results from earlier studies (Xuan et al. 2000; Natsagdorj et al. 2003; Kurosaki and Mikami 2005).

\subsection{Inter-Annual Variations}

Inter-annual variations in dusty days, dust storm days, strong wind days, and precipitation averaged over Mongolia are illustrated in Fig. 3. Frequent dust events occurred in 2006, 2008, and 2009 during the study period. Less frequent dusty days occurred in 2003 and 2011. These findings are consistent with those of Lee and Sohn (2011). The years 2003, 2012, and 2013 were wetter years compared with other years. Fewer dust events may be correlated with the presence of higher rates of precipitation. Over the country as a whole, precipitation has increased in the past decade.

Because Mongolia is a large territory with pronounced differences in climate and land surface conditions, the dust event distribution over the country exhibits a heterogeneous spatiotemporal pattern (see also Fig. 2). The inter-annual variation in dusty days, dust storm days, strong wind days and precipitation in different natural zones are shown in Fig. 4. Drifting dust occurs fairly frequently (30 - 40 days) in the Gobi Desert and mountainous zones. Dust storms occur more frequently in the Gobi Desert and steppe zones and less frequently in the mountains and forest steppe zones.

Dusty days occur less frequent in the steppe than in the Gobi Desert, although the annual number of strong wind days is approximately 180 in these zones. That is because the 
steppe has higher levels of precipitation and vegetation canopy than the Gobi Desert. In contrast, strong winds occurred less, about 120 and 90 days in the mountains and forest steppe zones, respectively. Dusty days were approximately 40 and 30, respectively, with precipitation levels of 120 and $260 \mathrm{~mm}$. The precipitation patterns were generally similar in all zones. These patterns exhibited slightly increasing trends over the past 14 years. The highest rates were approximately $6.5 \mathrm{~mm}$ per year in the steppe and forest steppe zones.
The correlation coefficients between dusty days and both strong wind days and precipitation for different zones are listed in Table 1. In general, wind conditions primarily dictate the dust event frequencies throughout Mongolia. Dust events are significantly negatively correlated with the amount of precipitation in the Gobi Desert. There are small variations in land surface conditions such as vegetation cover, soil moisture, etc. (Nandintsetseg and Shinoda 2010). The finding of significant negative correlations between dusty

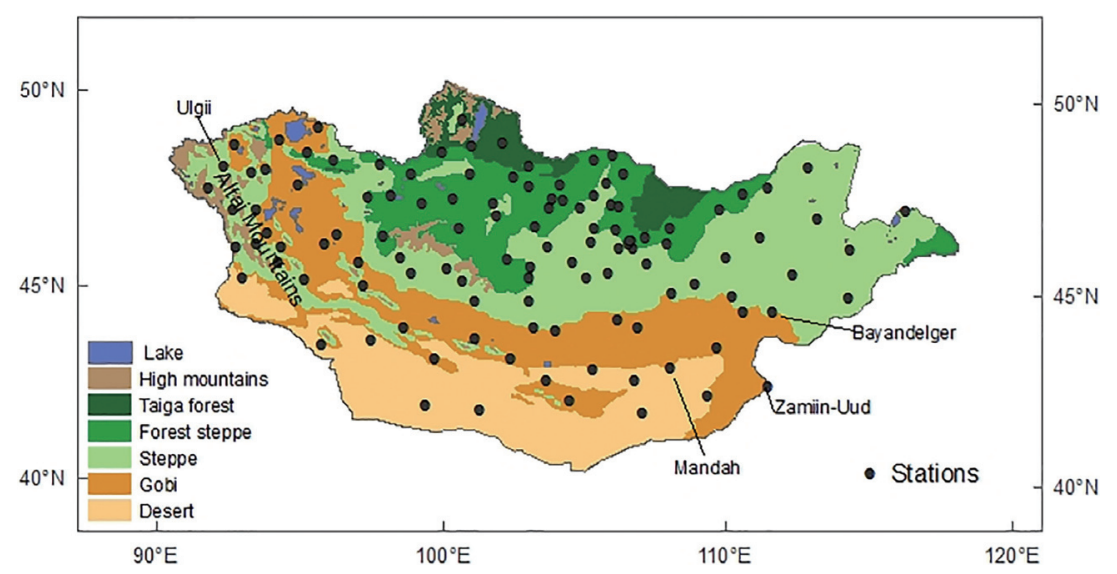

Fig. 1. Locations of meteorological station (black dots) are with natural zones in Mongolia (http://www.icc.mn/).

(a)

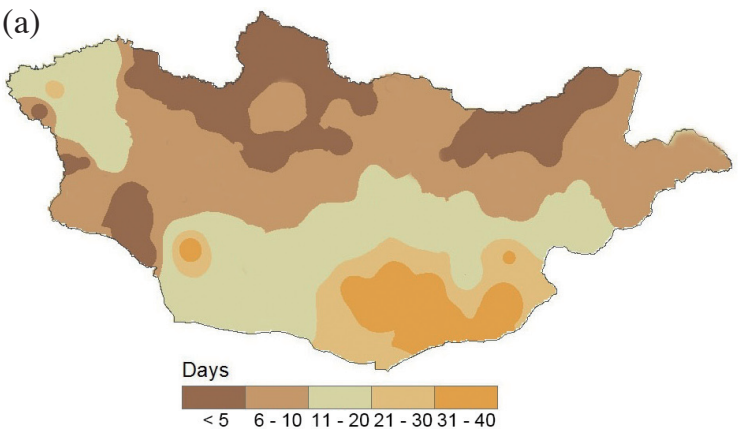

(b)

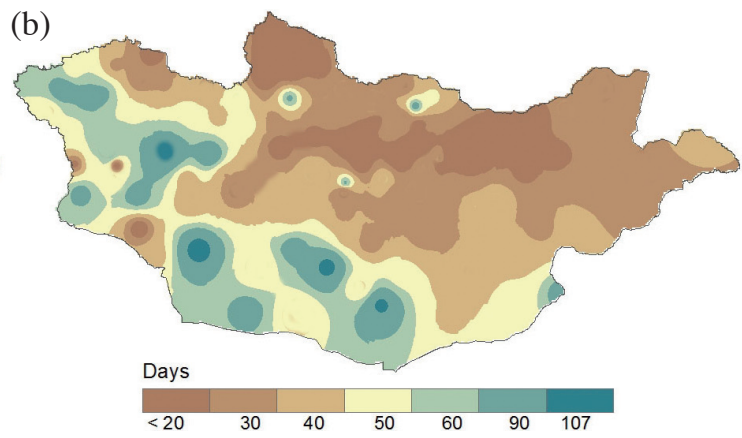

Fig. 2. Annual distributions are (a) dust storm days and (b) dusty days in 2000 - 2013.

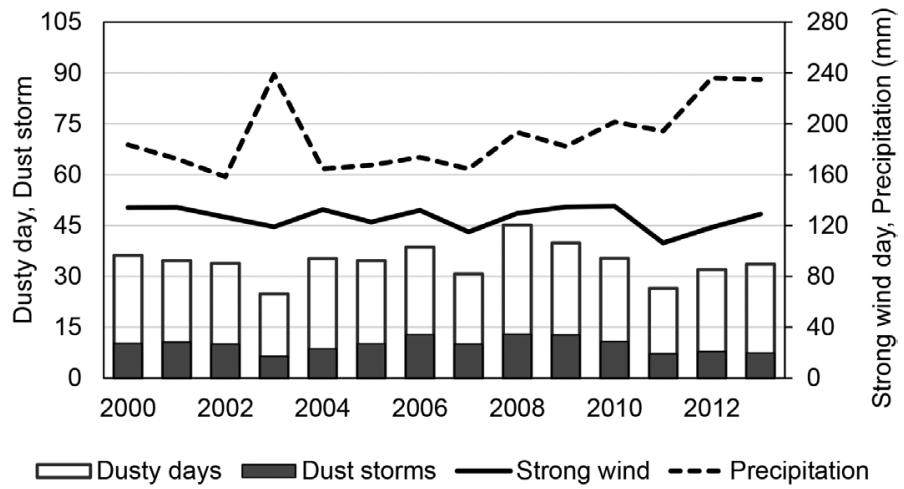

Fig. 3. Year-to-year annual variations of dusty days and dust storm days (left axis), and strong wind days, precipitation amount in mm (right axis). 

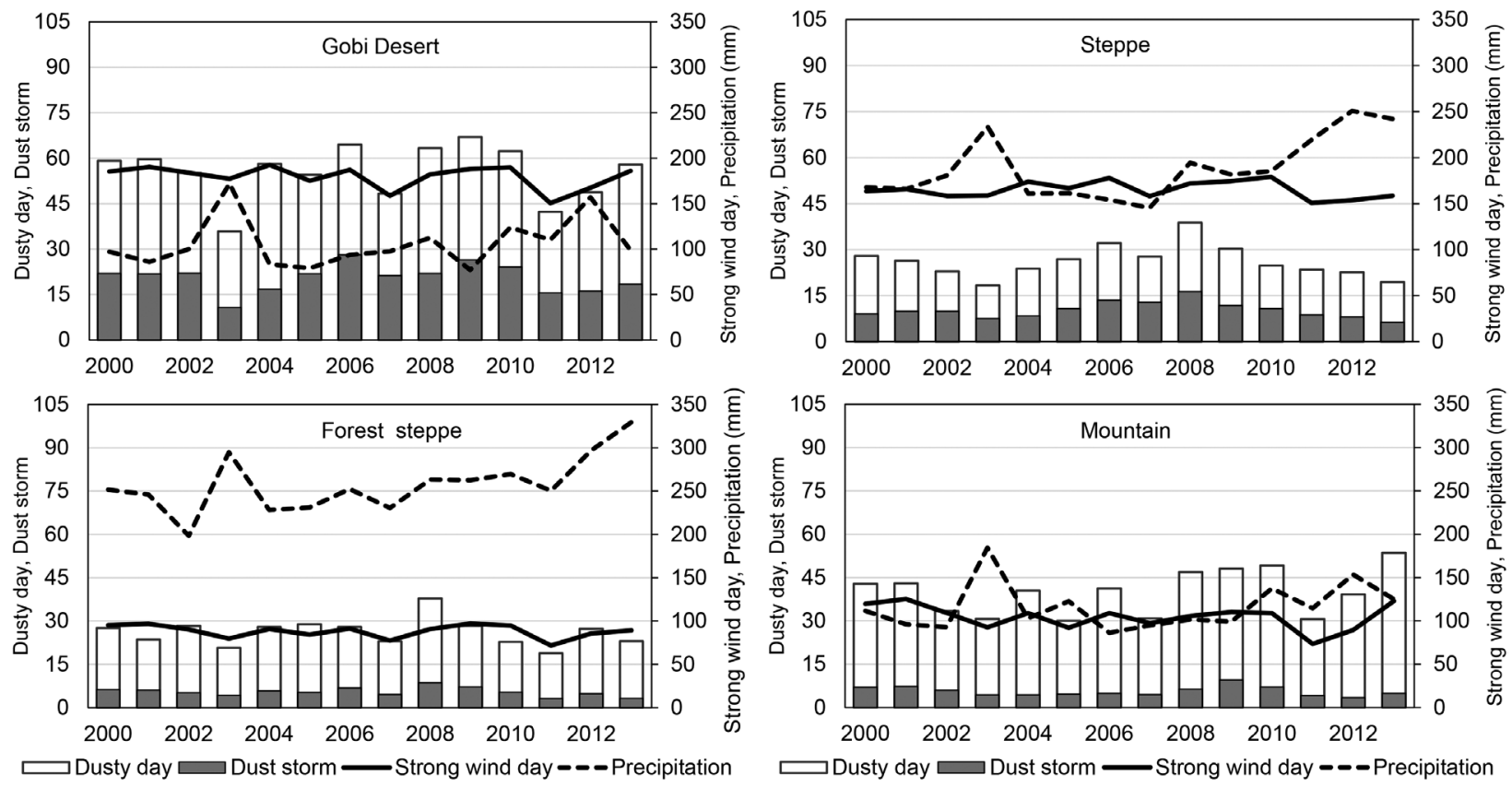

Fig. 4. The same as in Fig. 3 but for different natural zones.

Table 1. Correlation coefficients between annual dusty days and both strong wind days and precipitation in the different zones.

\begin{tabular}{c|ccc}
\hline Region (Sites) & Dusty days and strong wind & Dusty days and precipitation amount & Dusty days and days with precipitation \\
\hline Gobi Desert (24) & 0.71 & -0.64 & -0.40 \\
Steppe (26) & 0.54 & -0.51 & 0.19 \\
Forest Steppe (50) & 0.46 & -0.26 & 0.10 \\
Mountain (13) & 0.71 & -0.16 & -0.44 \\
\hline
\end{tabular}

days and precipitation implies that an increase in precipitation can suppress the occurrence of dust events. Likewise, a decrease in precipitation can induce more frequent dust emissions. The insufficient correlations with precipitation in other zones imply that other factors may be more important for further investigation (e.g., the effect of land surface conditions on dust formation is greater in grassland regions).

The correlation coefficients of dust events with the number of days with precipitation were weak in all zones. The result showed that there were no noticeable trends in the number of days with precipitation over of the course of the study period (data not shown).

\subsection{Seasonal Variations and Spatial Distribution}

Seasonal variations in dusty days, strong wind days, and precipitation are obvious in Mongolia. In general, 71.9\% of annual dust events occur in the spring (March - May), and the secondary weaker peak (6.6\%) occurs in autumn (September - November). The seasonal distribution pattern of strong winds is quite similar to the dusty day distribution. In terms of seasonal variations in precipitation, about $80 \%$ of the annual precipitation falls between April and September in Mongolia. The largest amount of precipitation falls in the forest steppe and steppe zones. The least precipitation falls in the Gobi Desert and mountains.

The numbers of dusty day have been greater in years of 2006, 2008, and 2009 than in the other 11 years studied and will hereafter be referred to as the dust-frequent years. Similarly, the least dusty years are termed as dustless years (2003 and 2011) and the other 9 years as dustmean years(2000 - 2002, 2004, 2005, 2007, 2010, 2012, and 2013). Figure 5 depicts comparisons of monthly dusty days, strong wind days, and precipitation in the specified periods. Actually, dust events occur throughout the year all over the country, although there are fewer dusty days under appropriate conditions in the winter and summer. Dust events occur 1 - 2 days more throughout the year in the Gobi Desert and mountain zones in dust-frequent years. Dust events occur more frequently between January and June in the steppe and forest steppe zones. There is no pronounced difference in the amount of precipitation between dust-frequent years and 

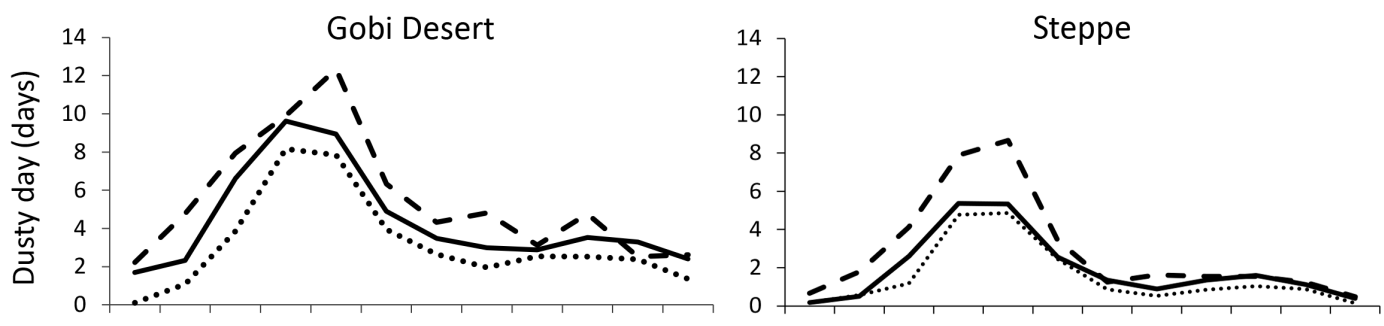

Jan Feb Mar Apr May Jun Jul Aug Sep Oct Nov Dec

Jan Feb Mar Apr May Jun Jul Aug Sep Oct Nov Dec

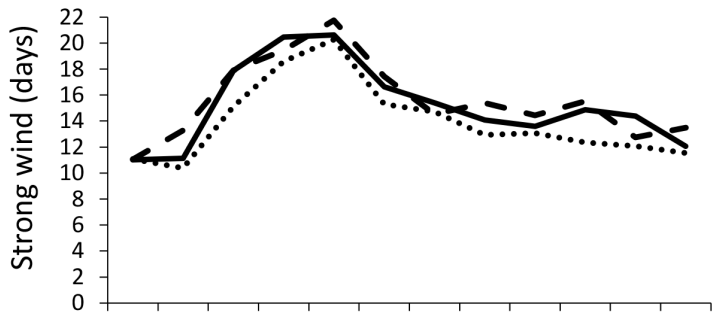

Jan Feb Mar Apr May Jun Jul Aug Sep Oct Nov Dec

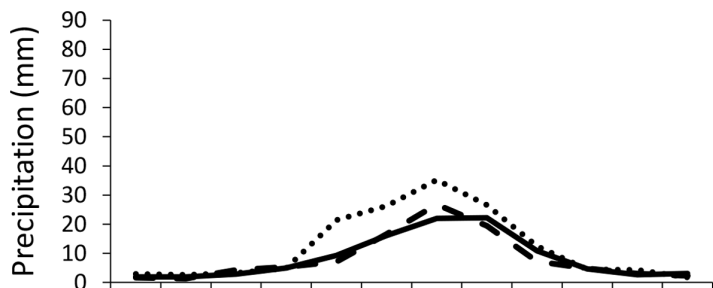

Jan Feb Mar Apr May Jun Jul Aug Sep Oct Nov Dec

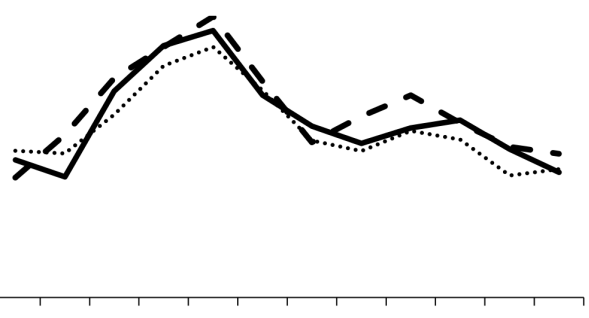

Jan Feb Mar Apr May Jun Jul Aug Sep Oct Nov Dec

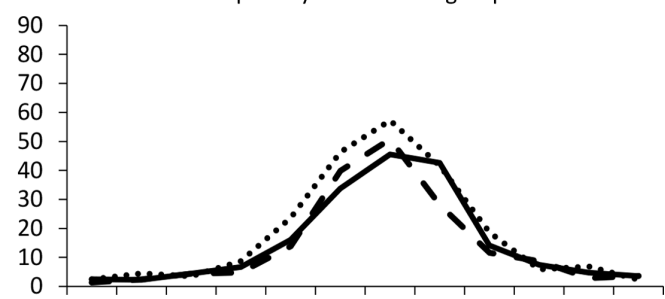

Jan Feb Mar Apr May Jun Jul Aug Sep Oct Nov Dec
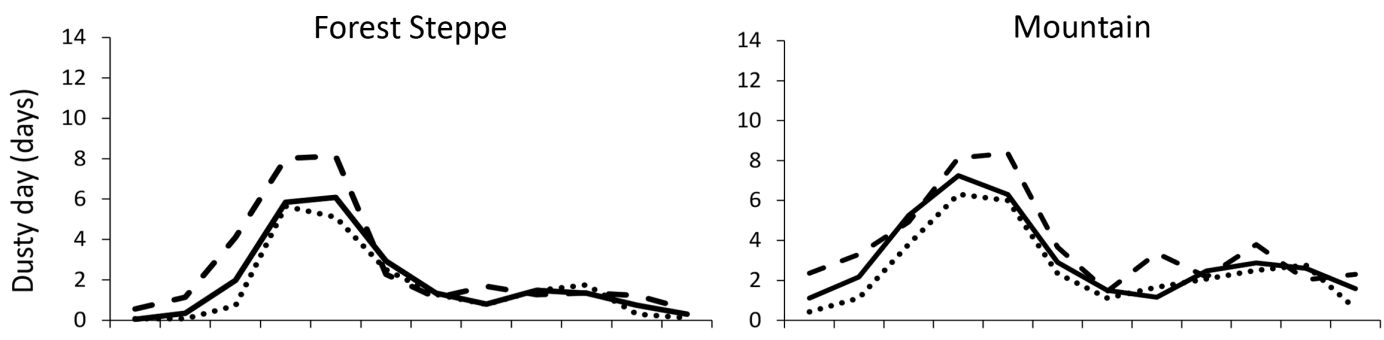

Jan Feb Mar Apr May Jun Jul Aug Sep Oct Nov Dec

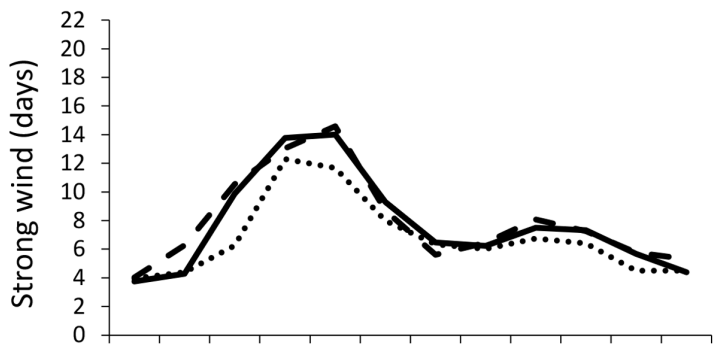

Jan Feb Mar Apr May Jun Jul Aug Sep Oct Nov Dec

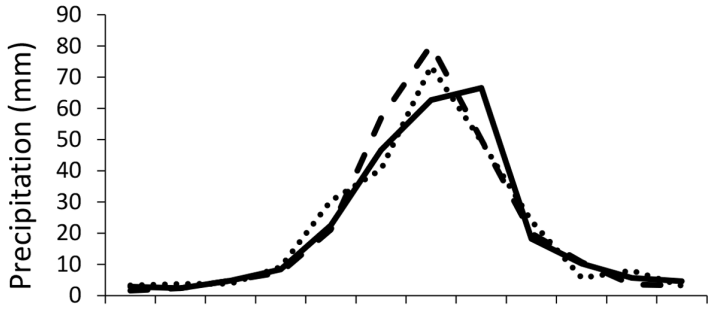

Jan Feb Mar Apr May Jun Jul Aug Sep Oct Nov Dec
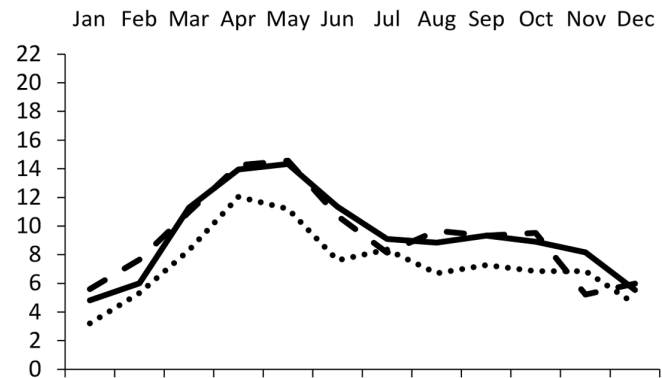

Jan Feb Mar Apr May Jun Jul Aug Sep Oct Nov Dec
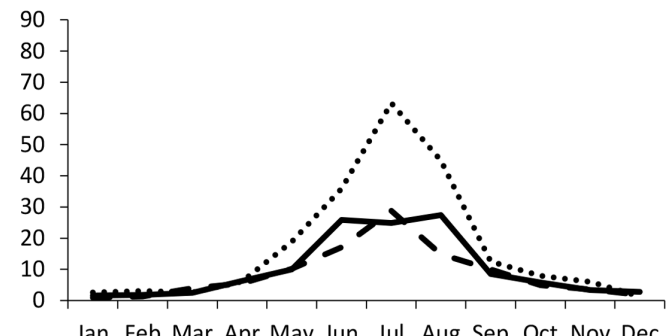

Jan Feb Mar Apr May Jun Jul Aug Sep Oct Nov Dec

— dust-mean year _ _ - dust-frequest year $\quad$....... dust-less year

Fig. 5. Comparison of monthly dusty days, strong wind days, and precipitation in the specified years in different natural zones. 
dust-mean years in Mongolia. This finding implies that frequent dust occurrences correspond to the slightly increased strong wind days. Conversely, dusty days were $1-2$ days fewer over all of Mongolia in dust-less year corresponding to fewer strong wind days and larger amounts of precipitation falling in the summer (May - August), as shown in Fig. 5. It is possible that dust occurrences are a likely result of effects of other than wind, especially in the Gobi Desert and steppe zones in May. In order to better understand the impact of precipitation on dust occurrences, more research such as the threshold for wind and dust formation after falling precipitation should be conducted in the future.

Figure 6 illustrates the spatial distribution of dusty days, strong wind days, and precipitation in the periods noted above. In general, strong wind days are distributed from the northwest to the southeast with increasing values (middle column in Fig. 6). The precipitation distribution varies considerably with annual amounts ranging from $50-400 \mathrm{~mm}$ from the southwest to the northeast (right column in Fig. 6), and the pattern of this distribution is roughly similar to the distribution of dusty days with correspondence with frequent dusty days with less precipitation.

Based on these results, the obviously frequent dusty days found in southeastern Mongolia correspond with the increased strong wind days in dust-frequent years (upper panel in Fig. 6). This fact implies that dusty days are controlled by strong wind days when precipitation is near to mean (approximately $150 \mathrm{~mm}$ in this area). In contrast, dusty days were less frequent in eastern Mongolia in dustless year (bottom panel in Fig. 6). The fewer dust events were potentially suppressed by increased precipitation found in southeastern Mongolia, as shown in the bottom panel of Fig. 6.

\subsection{Potential Dust Index}

Aeolian dust is typically generated by the presence of strong surface wind with plenty of dust on a dried surface. Although dust events occur frequently in the Gobi Desert zone, they occur throughout Mongolia in the spring. According to the previous section analyses, strong wind days and precipitation can both be significant parameters of dust events. Here, we attempt to create a potential dust index (PDI) to predict the likelihood of dust occurrences in spring season based on the correlations between dusty days and both strong wind days and precipitation. It can be defined as
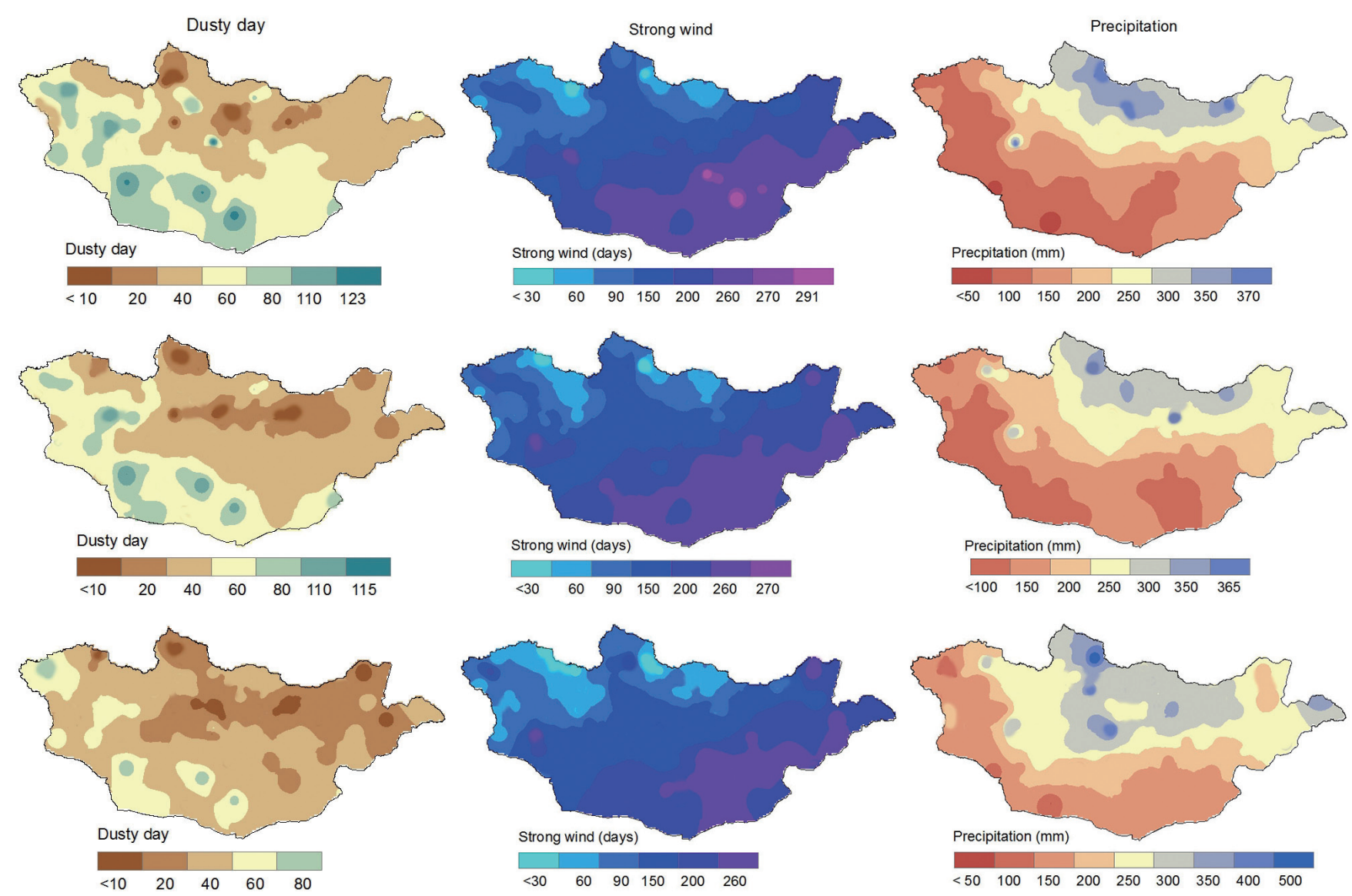

Fig. 6. Spatial distributions of dusty days, strong wind days, and precipitation in dust-frequent years (upper panel), dust-mean years (middle panel), and dust-less years (bottom panel). 
$\mathrm{PDI}=w_{1} p_{1}+w_{2} p_{2}$

where, $w_{1}$ and $w_{2}=$ refer to normalized weighting factors for strong wind days and precipitation, respectively. These factors are defined correlation coefficients between dust events and both strong wind days and precipitation. $p_{1}$ and $p_{2}$ stand for the normalized values of strong wind days and precipitation, respectively. The normalization of $p_{1}$ can be expressed as

$p_{1}=\frac{p_{i}-p_{\min }}{p_{\max }-p_{\min }}$

where, $p_{i}=$ the strong wind days corresponding to $i$-year from $2000-2013, p_{\min }$ and $p_{\max }=$ the minimum and maximum strong wind days in the 2000 - 2013 period. $p_{2}$ can be expressed the same as $p_{1}$ but for precipitation.

We calculated the weighting factors and the normalized values for each station. The spatial distribution of the correlation coefficients between dusty days and the PDI in spring (March - May) is shown in Fig. 7. The majority of areas in Mongolia are well represented with the correlation coefficients exceeding 0.50 . The physical meaning of PDI can be understood by considering that frequent surface strong winds and less precipitation are conditions favoring dust formation. Weaker relationships were found in northern Mongolia. Table 2 demonstrates that the slightly positive differences between the correlation coefficients for dusty days with PDI and those with strong wind days were found all over Mongolia. Therefore, the correlations between dusty days and PDI are intended to present the precipitation effect on dust occurrences. These results indicate that regional precipitation may have an impact on dust events. In fact, these results suggest that the PDI can be applied to the Gobi Desert, steppe and mountain zones in the spring. In order to provide a more detailed examination, the time series for PDI and dusty days is shown in Fig. 8 for selected stations (denoted in Fig. 1) and they were consistent with each other except for dusty days at Mandah and Bayandelger stations in 2008, at Ulgii in 2004, at Zamiin-Uud in 2005. Dusty days in those years should be discussed in a future work because this study focuses on dusty days, surface wind and precipitation.

\subsection{Regional Trend of Dust Event}

Figure 9 illustrates the linear trends for dusty days, strong wind days and precipitation based on year-to-year variations over the period 2000 - 2013. The trend for dusty days increasing by 1 - 5 days per year found in the central and southern parts of Mongolia resulted from strong wind days increasing by 2 - 6 days per year. Decreasing trends in dusty days ( 1 - 4 days per year) were recovered in the west and central parts of northern Mongolia. Precipitation decreasing by $0-8 \mathrm{~mm}$ per year were distributed in southwestern Mongolia and near Khuvsgul Lake. Most of the areas of Mongolia exhibited increased precipitation trends

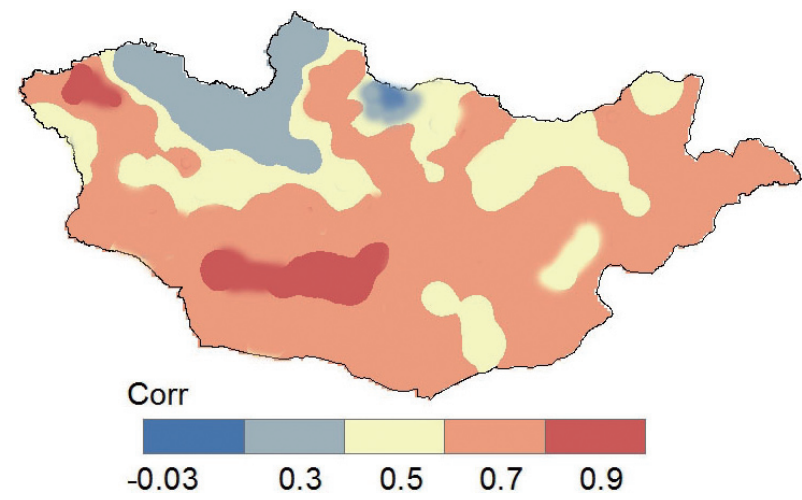

Fig. 7. Spatial patterns of the correlation coefficients between dusty days and the PDI.

Table 2. Correlation coefficients between dusty days and both strong wind days and PDI in the spring.

\begin{tabular}{c|cc}
\hline Region (Sites) & Dusty days and strong wind & Dusty days and PDI \\
\hline Gobi Desert (24) & 0.77 & 0.82 \\
Steppe (26) & 0.66 & 0.68 \\
Forest Steppe (50) & 0.59 & 0.78 \\
Mountain (13) & 0.67 & 0.79 \\
\hline
\end{tabular}



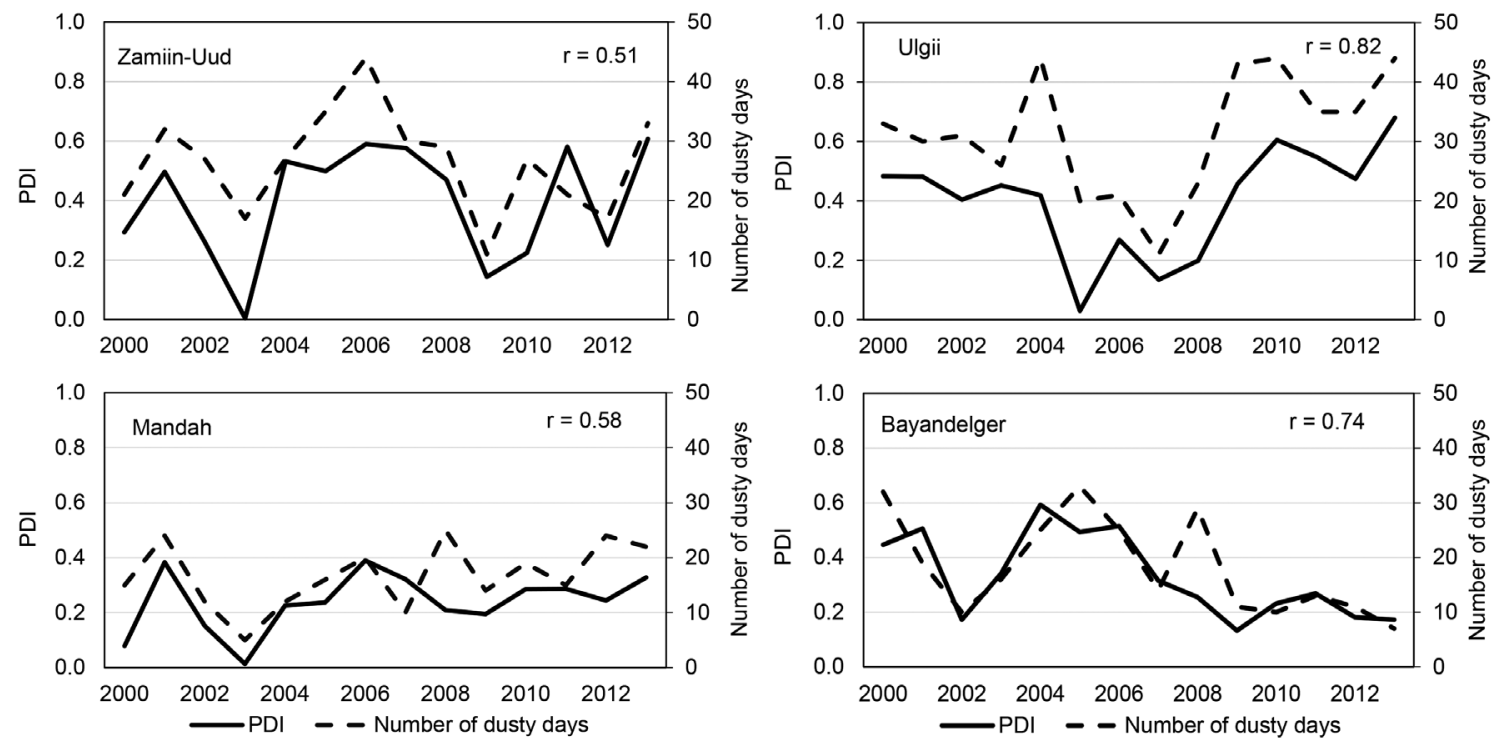

Fig. 8. The time series of the PDI and dusty days are at the stations denoted in Fig. 1.
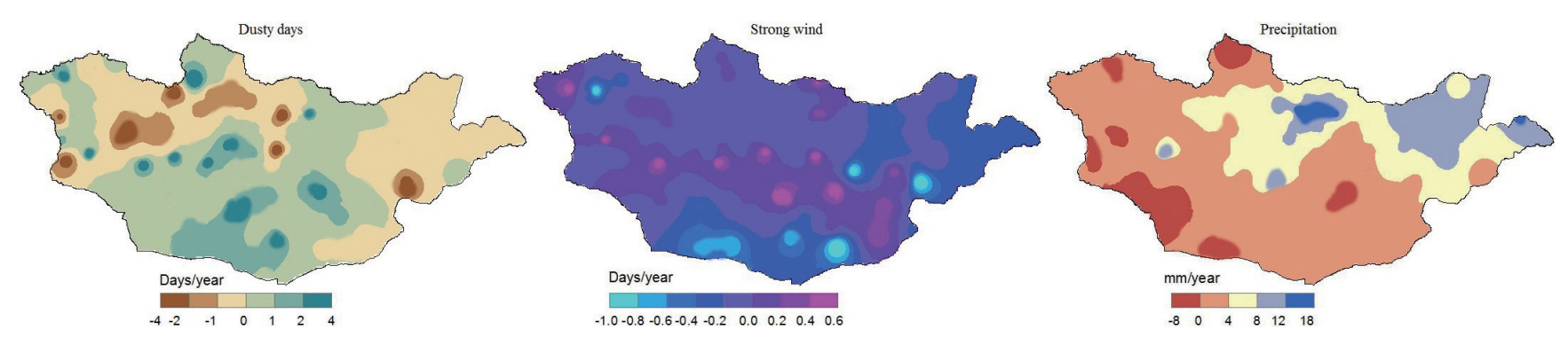

Fig. 9. Regional trends in dusty days, strong wind days, and precipitation.

(2 - $4 \mathrm{~mm}$ per year), particularly northeastern and eastern Mongolia (6 - $19 \mathrm{~mm}$ per year). A notable decrease in precipitation of $3-8 \mathrm{~mm}$ per year was noted in northern Mongolia around the Khuvsgul Lake; dusty days and strong wind days were considerably increased in this region.

We note that not all regions will react in the same way to climate change - some, for example, may become wetter and less dusty; while others may become drier with more dust events. There is a disagreement in an area with an increased number of dusty days corresponding to a decreasing strong wind days and increasing precipitation was found in southern Mongolia. It may be linked to human activities in land use, such as pastoral practices (e.g., more cashmere goats) and the last decade increase in the Mongolian mining industry.

\section{CONCLUSIONS}

This study presented the spatiotemporal distribution of dust events in Mongolia. We analyzed regional differences in the relationships among dusty days, surface wind and precipitation in Mongolia over the period 2000 - 2013. An- nual dust storm distributions consisting of less than 5 days were found over the forest steppe zone in northern Mongolia, a region with dense vegetation, high precipitation and low wind energy. Areas with dust storms more than 30 days included southeast and western Mongolia.

Large amounts of precipitation ( $>15 \mathrm{~mm}$ by averaged) can suppress the occurrences of dust event in May when strong wind days is similar to that of the mean ( 20 days) in the Gobi Desert and steppe zones.

We found that the PDI can well represent the variability and tendency of dust events over the majority of areas in Mongolia in the spring. In particular, dust events can potentially be predicted in the Gobi Desert and steppe zones. However, more factors should be considered in such predictions (e.g., soil conditions like vegetation and snow cover) in northern Mongolia.

Based on data from 2000 - 2013, an increasing dusty days by 1 - 5 days per year were found in the central parts of Mongolia and around Khuvsgul Lake. These events correspond to increased strong wind days. We also noted increasing trends in dusty days locally in northern and southern 
Mongolia. Human activities may have had an important effect on dust events in some parts of these areas. The decreasing strong wind days found in southern Mongolia is inconsistent with the increasing dusty days and precipitation. It is possible to link recent increases in primary mining industries (gold, coal, copper) according to the report of the National Statistical Office of Mongolia (NSOM 2013) in these areas in recent years. In fact, the soil in these areas exhibits increased erodibility (i.e., the soil and land surface being more vulnerable to wind).

Acknowledgements The authors thank the Institute of Meteorology and Hydrology of Mongolia and Center for Space and Remote Sensing Research (CSRSR), National Central University, Taiwan for providing relevant satellite and meteorological data. Also the authors want to thanks the great help from the Meteorological Satellite Lab, CSRSR.

\section{REFERENCES}

Batima, P. and D. Dagvadorj, 2000: Climate Change and Its Impacts in Mongolia, NAMHEM JEMR publishing, Ulaanbaatar, 15 pp.

Chen, Y. S., P. C. Sheen, E. R. Chen, Y. K. Liu, T. N. Wu, and C. Y. Yang, 2004: Effects of Asian dust storm events on daily mortality in Taipei. Environ. Res., 95, 151-155, doi: 10.1016/j.envres.2003.08.008. [Link]

Goudie, A. S., 1983: Dust storm in space and time. Prog. Phys. Geogr., 7, 502-530, doi: 10.1177/030913338300700402. [Link]

Goudie, A. S. and N. J. Middleton, 2006: Desert Dust in the Global System, Springer, 288 pp.

Hara, Y., I. Uno, and Z. Wang, 2006: Long-term variation of Asian dust and related climate factors. Atmos. Environ., 40, 6730-6740, doi: 10.1016/j.atmosenv.2006.05.080. [Link]

IMH (Institute of MeteorologyandHydrology of Mongolia), 2009: Meteorological Observations (in Mongolia), NAMHEM, Ulaanbaatar.

IPCC, 2007: Climate Change 2007: Synthesis Report, Contribution of Working Groups I, II and III to the Fourth Assessment Report of the Intergovernmental Panel on Climate Change, IPCC, Geneva, Switzerland, 104 pp.

Iwasaka, H. 2006: Impact of interannual variability of meteorological parameters on vegetation activity over Mongolia. J. Meteorol. Soc. Jpn., 84, 745-762, doi: 10.2151/jmsj.84.745. [Link]

Kurosaki, Y. and M. Mikami, 2003: Recent frequent dust events and their relation to surface wind in East Asia. Geophys. Res. Lett., 30, 1726-1736, doi: 10.1029/2003GL017261. [Link]

Kurosaki, Y. and M. Mikami, 2005: Regional difference in the characteristic of dust event in East Asia: Relationship among dust outbreak, surface wind, and land sur- face condition. J. Meteorol. Soc. Jpn., 83A, 1-18, doi: 10.215/jmsj.83A.1. [Link]

Kwon, H. J., S. H. Cho, Y. Chun, F. Lagarde and G. Pershagen, 2002: Effects of the Asain dust events on daily mortality in Seoul, Korea. Environ. Res., 90, 1-5, doi: 10.1006/enrs.2002.4377. [Link]

Lee, E. H. and B. J. Sohn, 2011: Recent increasing trend in dust frequency over Mongolia and inner Mongolia regions and its association with climate and surface condition change. Atmos. Environ., 45, 4611-4616, doi: 10.1016/j.atmosenv.2011.05.065. [Link]

Lin, C. Y., S. C. Liu, C. K. Chou, T. H. Liu, C. T. Lee, C. S. Yuan, C. J. Shiu, and C. Y. Young, 2004: Long-range transport of Asian dust and air pollutants to Taiwan. Terr. Atmos. Ocean. Sci., 15, 759-784, doi: 10.3319/ TAO.2004.15.5.759(ADSE). [Link]

Liu, G. R. and T. H. Lin, 2004: Application of geostationary satellite observations for monitoring dust storms of Asia. Terr. Atmos. Ocean. Sci., 15, 825-837, doi: 10.3319/TAO.2004.15.5.825(ADSE). [Link]

Loveland, T. R., B. C. Reed, J. F. Brown, D. O. Ohlen, Z. Zhu, L. Yang, and J. W. Merchant, 2000: Development of a global land cover characteristics database and IGBP DISCover from 1-km AVHRR data. Int. J. Rem. Sens., 21, 1303-1330, doi: 10.1080/014311600210191. [Link]

MARCC, 2010: MONGOLIA: Assessment Report on Climate Change, Ministry of Nature, Environment and Tourism, Ulaanbaatar, $55 \mathrm{pp}$.

McKendry, I. G., J. P. Hacker, R. Stull, S. Sakiyama, D. Mignacca, and K. Reid, 2001: Long-range transport of Asian dust to the Lower Fraser Valley, British Columbia, Canada. J. Geophys. Res., 106, 18361-18370, doi: 10.1029/2000JD900359. [Link]

Miller, R. L., I. Tegen, and J. Perlwitz, 2004: Surface radiactive forcing by soil dust aerosols and the hydrologic cycle. J. Geophys. Res., 109, D04203, doi: 10.1029/2003JD004085. [Link]

Nandintsetseg, B. and M. Shinoda, 2010: Seasonal change of soil moisture in Mongolia: Its climatology and modelling. Int. J. Climatol., 31, 1143-1152, doi: 10.1002/joc.2134. [Link]

Natsagdorj, L, 2009: Drought and Zud (in Mongolian), BEMBI SAN publishing, Ulaanbaatar, $62 \mathrm{pp}$.

Natsagdorj, L., D. Jugder, and Y. S. Chung, 2003: Analysis of dust storms observed in Mongolia during 19371999. Atmos. Environ., 37, 1401-1411, doi: 10.1016/ S1352-2310(02)01023-3. [Link]

NSOM (National Statistical Office of Mongolia), 2013: Repot 2012, Ulaanbaatar.

Park, S. U., L. S. Chang, and E. H. Lee, 2005: Direct radiative forcing due to aerosols in East Asia during a Hwangsa (Asian Dust) event observed on 19-23 March 2002 in Korea. Atmos. Environ., 39, 2593-2606, doi: 
10.1016/j.atmosenv.2005.01.041. [Link]

Puntsagdorj, C., 2014: Meteorological Observations Manual 14 (in Mongolian), NAMHEM, Ulaanbaatar, 8 pp.

Shao, Y. and C. H. Dong, 2006: A review on East Asian dust storm climate, modelling and monitoring. Global Planet. Change, 52, 1-22, doi: 10.1016/j.gloplacha.2006.02.011. [Link]

Sun, J., M. Zhang, and T. Liu, 2001: Spatial and temporal characteristics of dust storms in China and its surrounding regions, 1960-1999: Relations to source area and climate. J. Geophys. Res., 106, 10325-10333, doi: 10.1029/2000JD900665. [Link]

Tegen, I. and I. Fung, 1995: Contribution to the atmospheric mineral aerosol load from land surface modification. J. Geophys. Res., 100, 18707-18726, doi: 10.1029/95JD02051. [Link]

Tian, S. F., M. Inoue, and M. Du, 2007: Influence of dust storm frequency in northern China on fluctuations of Asian dust frequency observed in Japan. SOLA, 3, 121124, doi: 10.2151/sola.2007-031. [Link]

Uno, I., Z. Wang, M. Chiba, Y. S. Chun, S. L. Gong, Y. Hara, E. Jung, S. S. Lee, M. Liu, M. Mikami, S. Music, S. Nickovic, S. Satake, Y. Shao, Z. Song, N. Sugimoto, T. Tanaka, and D. L. Westphal, 2006: Dust model intercomparison (DMIP) study over Asia: Overview. J. Geophys. Res., 111, D12213, doi: 10.1029/2005JD006575. [Link]

Xuan, J., G. Liu, and K. Du, 2000: Dust emission inventory in Northern China. Atmos. Environ., 34, 4565-4570, doi: 10.1016/S1352-2310(00)00203-X. [Link]

Zou, X. K. and P. M. Zhai, 2004: Relationship between vegetation coverage and spring dust storms over northern China. J. Geophys. Res., 109, D03104, doi: 10.1029/2003JD003913. [Link] 